\title{
ILMU NAHWU DAN PENGARUHNYA TERHADAP ISTINBAT HUKUM FIKIH
}

\section{NAHWU SCIENCE AND ITS EFFECT AGAINTS THE LEGAL OF ISTINBĀT OF ISLAMIC JURISPRUDENCE}

\author{
Zulfiah Sam \\ Sekolah Tinggi Ilmu Islam dan Bahasa Arab (STIBA) Makassar \\ Email: zulfiahsam@stiba.ac.id \\ Saadal Jannah \\ Sekolah Tinggi Ilmu Islam dan Bahasa Arab (STIBA) Makassar \\ Email: saadaljannah@stiba.ac.id \\ Wahyuni Ishak \\ Sekolah Tinggi Ilmu Islam dan Bahasa Arab (STIBA) Makassar \\ Email: wahyuniishak05@gmail.com
}

\begin{tabular}{|c|c|}
\hline Keywords : & ABSTRACT \\
\hline $\begin{array}{l}\text { jurisprudence, law science, } \\
\text { istinbath, nahwu }\end{array}$ & $\begin{array}{l}\text { This research aimed to examine the metters surrounding the science } \\
\text { of Nahwu in the form of understanding, the law of studying it and its } \\
\text { virtue as seen from its position in syar'i science and its effect on the } \\
\text { istinbat of fiqh laws. The method used in this research was library } \\
\text { research. The result of this study indicated that the sciences of } \\
\text { Nahwu has major influence on the istinbath of laws related to fiqh } \\
\text { issues, such as the differences between Syafi'iyah and Malikiyah on } \\
\text { the problem of mandatory head sweeping when ablution, differences } \\
\text { in Jumhur Ulama on the problem of how to purify the feet when } \\
\text { performing ablution, whether to wash them. Or it is enough just to } \\
\text { wipe it, as well as the differnces between Syafi'iyah and Hanafiyah in } \\
\text { the problem of the fetus that was slaughtered by its mother. }\end{array}$ \\
\hline
\end{tabular}

\begin{tabular}{|c|c|}
\hline Kata kunci : & ABSTRAK \\
\hline $\begin{array}{l}\text { hukum fikih, ilmu Nahwu, } \\
\text { istinbat. }\end{array}$ & 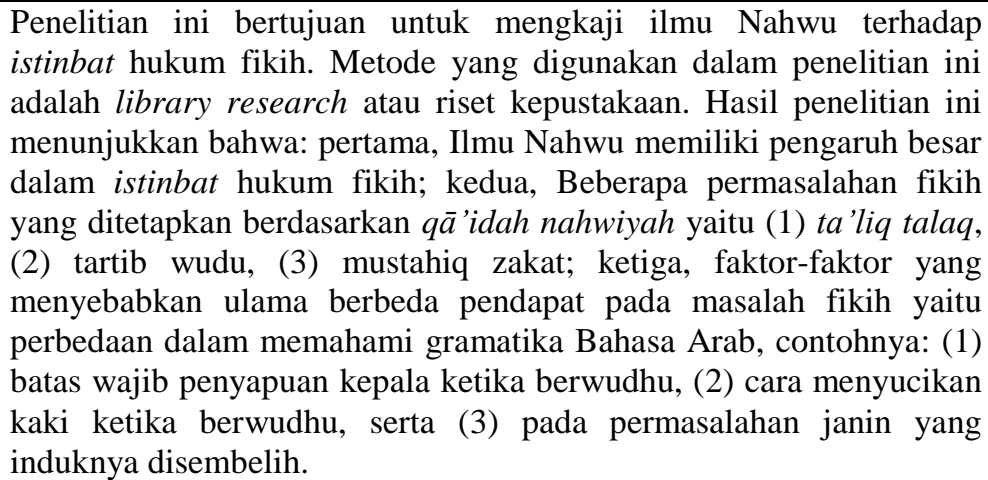 \\
\hline
\end{tabular}

Diterima: 3 Februari 2021; Direvisi: 31 Mei 2021; Disetujui: 1 Juni 2021; Tersedia online: 11 Juni 2021

How to cite: Zulfiah Sam, Saadal Jannah, dan Wahyuni Ishak. "Ilmu Nahwu dan Pengaruhnya Terhadap Istinbat Hukum Fikih." NUKHBATUL 'ULUM: Jurnal Bidang Kajian Islam 7, no. 1 


\section{PENDAHULUAN}

Kajian ilmu Nahwu -selain ilmu-ilmu lainnya- dianggap sebagai pengantar dan pondasi bagi keilmuwan seseorang. ${ }^{1}$ Ilmu Nahwu juga disebutkan sebagai ilmu paling dasar yang harus diketahui oleh seorang calon sarjana dan ilmuwan muslim. ${ }^{2}$ Ilmu Nahwu juga sebagai salah satu $u s ̣ u l$ istinbat dalam kajian bahasa $u s ̣ u l$ Fikih, dari sebuah teori menjadi sebuah hukum fikih yang aplikatif. ${ }^{3}$ Pentingnya ilmu Nahwu dalam agama Islam, juga sampai pada andil penetapan hukum suatu permasalahan dalam hukum Islam.

Bahasa Arab memiliki berbagai macam cabang ilmu, salah satunya adalah ilmu Nahwu. Kebanyakan penuntut ilmu jika mendengar istilah ini seketika membayangkan tingkat kesulitannya di atas cabang ilmu yang lain, sehingga membuat mereka enggan mempelajari dan mendalaminya. Bahkan kita dapati sebahagian dari mereka teramat semangat mempelajari ilmu hadis, fikih, tafsir dan meninggalkan ilmu qawaid bahasa Arab. Mereka beranggapan bahwa ilmu-ilmu tersebutlah yang secara nyata dapat memberikan petunjuk pada setiap permasalahanpermasalahan yang ada, adapun ilmu Nahwu secara khusus atau qawaid lughawiyah secara umum hanya sebatas alat agar bisa berkomunikasi menggunakan bahasa Arab dengan baik dan benar.

Secara bahasa, kata "Nahwu" memiliki banyak makna, di antaranya adalah al qashd/ tujuan, al bayan/penjelasan, al jihah/sisi, al syabh/seperti, al nau'/jenis, dan ba'dh/sebagian. Beberapa makna tersebut terkumpul dalam bait syair: ${ }^{4}$

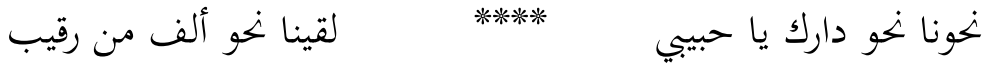

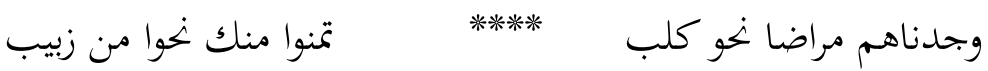

kami melangkah ke arah rumahmu wahai kekasihku kami bertemu sekitar seribu penjaga

kami dapati mereka dalam keadaan lemah seperti anjing yang mengharap darimu sebahagian dari kismis

${ }^{1}$ Ahmad, “Artikulasi Ilmu Nahwu Dalam Kehidupan (Studi Analisis Makna I'rab Kitab Al Jurumuyah Menggunakan Semantika Dalalah Lafzhiyah Dalam Ushul Fikih,” Jurnal Pendidikan Dan Pranata Islam, SYAIKHUNA 10, no. 2 (2019): 194.

${ }^{2}$ Yahya al-Imrithy, Nazham Al Jurumiyah Al Imrity (Maktabah Islamiyah, n.d.). Tesis, 2021.

3 Syarif Muhammad Yahya, "Kontribusi Kaidah-Kaidah Nahwu Terhadap Ushul Fikih,"

${ }^{4}$ Abdullah Bin Ahmad al-Fakihi, Syarah Kitab al-Hudud Fi al-Nahwi (Maktabah Wahbah, n.d.). 
Nahwu adalah mashdar dari nahaa-yanhuu-nahwan (نحا-ينحو-نحو) lalu dikhususkan untuk penyebutan ilmu ini. Sebagaimana kata fiqh, dia adalah mashdar dari kata faqiha-yafqahu-fiqhan artinya pemahaman, lalu dikhususkan untuk penyebutan ilmu halal dan haram dalam syariat. ${ }^{6}$ Kebanyakan ulama berkata mengenai asal usul penamaan ilmu Nahwu bahwa ia diambil dari perkataan 'Ali bin Abi Thalib kepada Abul Aswad al-Duali setelah beliau memperlihatkan kepadanya sebuah lembaran yang berisi "kalam adalah isim, fi'il, huruf dan seterusnya", beliau berkata,

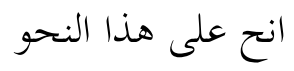

Artinya:

"Buatlah yang semisal dengan ini." 7

Menurut istilah, Nahwu adalah ilmu yang dengannya, benar dan salah dari susunan kalimat dalam bahasa Arab dan keadaan lafaz-lafaz yang membentuknya dapat diketahui. ${ }^{8}$ Ulama yang lain mengatakan bahwa Nahwu menurut istilah adalah ilmu yang mempelajari kaidah-kaidah yang berkaitan dengan hukum akhir setiap kata dalam bahasa Arab jika menjadi komponen pada sebuah kalimat, baik dari segi i'rab, bina dan sebagainya. ${ }^{9}$ Syekh Shalih al-Utsaimin dalam rekaman pelajaran Syarah Alfiyah Ibnu Malik juga memaparkan bahwa Nahwu secara istilah adalah ilmu yang mempelajari keadaan akhir setiap kata dari sisi i'rab dan bina-nya.

Peran ilmu Nahwu dalam pemahaman terhadap sumber ilmu syar'i (AlQur'an dan Sunah) menjadikan ia memiliki kedudukan tinggi dalam deretan ilmuilmu Islam. Bahkan Imam Nawawi menyebutkan bahwa ia sejajar dengan penyebutan ilmu fikih, hadis dan ilmu-ilmu syar' $i$ yang lain saat beliau menjelaskan tiga pembagian ilmu syar'i. Beliau berkata, "Bagian kedua adalah farḍ kifāyah, yaitu ilmu-ilmu yang wajib diketahui oleh manusia agar dapat memahami agamanya berupa ilmu-ilmu syar'i seperti mengahafal Al-Qur'an dan hadis beserta ilmu-ilmu yang terkait dengannya, ușul, fikih, nahwu, bahasa, sharf, serta ilmu mengetahui perawi hadis, masalah ijmak dan khilaf."

\footnotetext{
${ }^{6}$ Muhammad Bin Muhammad Bin Abd al-Razzaq al-Husainy, Taaj Al-'arus Min Jawahir AlQamu, 40th ed. (Daar Al Hidayah, n.d.).

${ }^{7}$ Syamsuddin Muhammad bin Ahmad al-Dzahaby, Taarikh Al-Islam Wa Wafayaat AlMasyaahir Wa Al-A 'lam (Bierut: Dar al-Kutub al-'Arabiy, n.d.).

${ }^{8}$ Muhammad Bin Ali Bin Muhammad Hamid, Mausu'ah Kasysyaf Al- Funn Wa Al-'Uluum, 1st ed. (Beirut: Maktabah Labnan Nasyirun, 1996).

${ }^{9}$ Muhammad Muhyiddin Abdul Hamid, Al-Tuhfah Al-Saniyah Bi Syarhi Muqaddimati AlAjrumiyah (Damaskus: Maktabah Darr Al-Fajr, n.d.).

${ }^{10}$ Muhyiddin Yahya bin Syaraf Al Nawawi, Al Majmu’ Syarah Al Muhazzab, 1st ed. (Dar al
} Fikri, n.d.). 
Imam Syafi'i berkata, "Siapa yang menyelam ke dalam lautan Nahwu, niscaya ia akan diberi petunjuk memahami seluruh ilmu." "11 Imam al-Suyuti berkata, "Ulama telah sepakat bahwa ilmu Nahwu adalah cabang ilmu yang dibutuhkan oleh seluruh cabang ilmu lainnya, terlebih lagi tafsir dan hadis. Sesungguhnya tidak boleh bagi seorang pun berbicara mengenai kitabullah dan sunah Rasulullah melainkan ia paham bahasa Arab karena Al-Qur'an berbahasa Arab. Olehnya, maknanya tidak mungkin dapat diketahui melainkan dengan pemahaman terhadap kaidah-kaidah bahasa Arab, demikian juga sunah Rasulullah shallallaahu 'alaihi wa sallam."12

Dari uraian di atas, pertanyaan yang muncul kemudian adalah bagaimana pengaruh ilmu Nahwu terhadap istinbat hukum fikih? Untuk menjawab permasalahan di atas, penelitian ini dilakukan dengan tujuan: (1) bagaimana pengaruh ilmu Nahwu terhadap penetapan hukum fikih?; (2) permasalahan fikih apa saja yang ditetapkan berdasarkan kaidah ilmu Nahwu?; (3) faktor apa yang menyebabkan ulama berbeda pendapat pada masalah fikih. Jawaban atas ketiga pertanyaan ini diharapkan dapat memberikan wawasan baru bahwa perbedaan pendapat dalam persoalan fikih yang furü'iyyah di kalangan para sarjana Islam diakibatkan oleh perbedaan pemahaman mereka terhadap ilmu Nahwu. Dengan demikian, penelitian berimplikasi bahwa penguasaan terhadap ilmu Nahwu ikut menentukan sikap seseorang dalam beragama. Ilmu Nahwu bukan hanya sekadar ilmu Bahasa sebagaimana dipahami kebanyakan orang, tetapi juga menentukan tingkat toleransi seseorang terhadap hukum fikih.

Adapun metode penelitian yang digunakan adalah library research atau riset kepustakaan, dimana penelitian ini mengupayakan penelusuran literatur yang ada dan menelaahnya secara teliti untuk memperoleh sumber-sumber yang berkenaan dengan objek kajian, yaitu peran penting ilmu Nahwu dalam agama Islam, dimana ia sampai pada andil penetapan hukum suatu permasalahan dalam hukum Islam dan menyanggah anggapan sebagian akademisi bahwa ilmu Nahwu hanyalah sebatas alat untuk bisa berkomunikasi menggunakan bahasa Arab dengan baik dan benar. Untuk pengumpulan data, penulis terlebih dahulu mengumpulkan sumber data primer dari Al-Qur'an dan hadis Rasulullah saw. sebagai bahan utama, kemudian dijelaskan oleh sumber data sekunder. Untuk beberapa pengertian, penulis menggunakan buku-buku rujukan berbahasa Arab sebagai sumber data sekunder.

Sejauh ini, penelitian tentang pengaruh ilmu Nahwu terhadap penetapan hukum fikih sudah banyak didokumentasikan oleh para peneliti. Abdurrahim bin alHasan bin Ali al-Isnawi al-Syafi'i menjelaskan bahwa ilmu Nahwu berpengaruh pada penetapan hukum fikih, terutama yang berkaitan dengan persoalan furu'iyah

${ }^{11}$ Abdul Hayyi bin Ahmad bin Muhammad, Syazaraat Al Dzahab Fi Akhbari Man Dzahab, 1st ed. (Beirut: Daar Ibnu Katsir, 1986).

${ }^{12}$ Muhammad al-Amiin Bin Abdullah al-Urami al-'Alawi, Al-Kaukab Al-Wahhaj Wa AlRaudh Al-Bahhaj Fi Syarhi Shahih Muslim Bin Hajjaj, 1st ed. (Daar al Minhaj, 2009). 
yang berdasarkan mazhab Syafi'i. Sulaiman bin Abdilqawiyy bin Abdilkarim alThufiy al-Sharshariy al-Hanbaliy mengungkapkan bahwa berbagai permasalahan istinbāt fikih didasarkan oleh ilmu Nahwu. Namun perbedaannya terletak pada latar belakang mazhab yang dianut. Jika Al-Isnawi menetapkan permasalahan dari mazhab Syafiiyah, Sulaiman hadir dengan mazhab Hambali. ${ }^{13}$ Penelitian lainnya dilakukan oleh Ali Nashir Muhammad dengan judul Atsaru al-Dilālati al-Nahwiyah wa al-Lugāwiyah fi Istinbāți al-Ahkāmi al-Fiqhiyah min Āyati al-Dain 'inda alMufassirīn. Pada kajian ini, penulis menghadirkan perbedaan pendapat ulama tafsir khususnya dalam masalah hutang-piutang yang terdapat dalam Al-Qur'an dan penetapan pendapat räjih yang sebagian besarnya didasari oleh kaidah-kaidah Nahwu. Di dalamnya, penulis menyebutkan enam poin permasalahan hutang piutang yang diperselisihkan oleh ulama. Selanjutnya, penelitian yang dilakukan oleh Ibrahim dan al-Na'im Muhammad Ahmad yang berjudul Atsaru al-Alaqati baina Ushuli al-Fiqhi wa Ușūli al-Nahwi fi Istinbāti al-Ahkāmi Al-Syar'iyah. Kajian ini mengungkapkan besar pengaruh ilmu Nahwu terhadap istinbath hukum-hukum dari sisi kuatnya hubungan antara ilmu Nahwu dan ilmu ushul fikih yang merupakan ilmu alat dalam meramu dalil sehingga menghasilkan suatu hukum. Penelitian yang dilakukan oleh Syarif Muhammad Yahya yang berjudul "Kontribusi Kaidah-Kaidah Nahwu terhadap Ușūl Fikih: Studi naskah dan telaah pemikiran Isnawi (772 H/1371M) dalam Kitab al-Kawakab al-Duri fi Takhrijil Furu' al-Fiqihiyyah ala alMasāil al-Nahwiyyah. Pada kajian ini, penulis mengkaji sejauh mana kaidah Nahwu berpengaruh pada Ușūl Fikih, dengan memahami langkah-langkah kontribusi teori Isnawi dalam metodologi takhrij furù' melalui Ilmu Nahwu dan pengaruhnya terhadap Ușūl Fikih, serta menjelaskan hubungan ilmu Bahasa (Nahwu) dan Syariat Islam. ${ }^{14}$ Penelitian yang berjudul "Artikulasi Ilmu Nahwu Dalam Kehidupan (Studi Analisis Makna I'rab Kitab al-Jurumiyah Menggunakan Semantika Dalālah Lafzhiyah dalam Ușūl Fikih" oleh Ahmad. Penelitian tersebut membahas artikulasi interralasi makna i'rab dalam gramatika bahasa dalam kehidupan sehari-hari menggunakan dalālah lafzhiyah dalam Ușūl Fikih. ${ }^{15}$

Namun demikian, dari semua penelitian tersebut belum ada yang membahas tentang pengaruh ilmu Nahwu dalam istinbat hukum fikih. Dalam penelitian ini, penulis mengkaji secara umum dan lebih luas yang dilengkapi dengan contoh-contoh permasalahan dari berbagai pembahasan dalam fikih seperti ibadah, muamalah dan mawarits, serta tidak monoton pada satu mazhab saja.

\footnotetext{
${ }^{13}$ Sulaiman bin Abdilqawiy al-Thufiy al-Sharsariy al-Hanbali, Al-Shaq'atu A-Gadhabiyah Fi Al-Raddi 'alaa Munkirii A- Arabiyah, 1st ed. (Al Waliy al Islamiy, 2013).

${ }^{14}$ Syarif Muhammad Yahya, "Kontribusi Kaidah-Kaidah Nahwu Terhadap Ushul Fikih Studi Naskah Dan Telaah Pemikiran Isnawi Dalam Kitab Al Kawakab Ad Duri Fi Takhrij Al Furu' Al Fiqhiyah 'ala Al Masaail Al Nahwiyah,” Tesis, 2021.

${ }^{15}$ Ahmad, "Artikulasi Ilmu Nahwu Dalam Kehidupan (Studi Analisis Makna I'rab Kitab Al Jurumuyah Menggunakan Semantika Dalalah Lafzhiyah Dalam Ushul Fikih.”
} 


\section{PEMBAHASAN}

\section{Pengaruh Ilmu Nahwu terhadap Istinbat Hukum Fikih}

Pemahaman kaidah ilmu Nahwu sangat berpengaruh dalam menentukan pemahaman nas-nas syariat yang benar dan sesuai dengan apa yang diinginkan Allah swt. dan Rasul-Nya, karenanya orang yang tidak memahami Nahwu dilarang untuk memberi Fatwa. ${ }^{16}$ Ulama menyebutkan bahwa ilmu fikih adalah ilmu tentang hukum-hukum syariat yang bersifat amaliyah (perbuatan) yang ditetapkan dari dalildalil terperinci. ${ }^{17}$ Dari pengertian itu, kita dapat melihat besarnya pengaruh ilmu Nahwu dalam penetapan hukum, hal ini sebagaimana ungkapan terakhir dari pengertian tersebut bahwa hukum-hukum syar'i itu ditetapkan dari dalil-dalil terperinci. Sementara kita mengetahui bahwa induk dalil dalam syariat adalah AlQur'an dan sunah dimana keduanya datang dengan berbahasa Arab dan memahaminya mesti dengan penguasaan terhadap kaidah-kaidah bahasa Arab.

Contoh keterkaitan ilmu Nahwu dengan pemahaman terhadap makna ayat dalam Al-Qur'an adalah pada penggunaan huruf $b a^{\prime}$. Huruf $b a^{\prime}$ (sebagai huruf $j \bar{a} r$ ) sangat sering kita temukan dalam Al-Qur'an, namun huruf $b a$ ' tidak hanya memiliki satu arti melainkan banyak arti yang hanya bisa dipahami oleh orang yang menguasai ilmu Nahwu. Ahmad Umar Abu Syaubah menyebutkan bahwa makna huruf $b a$ ' dalam Al-Qur'an ada empat belas, di antaranya:

\section{Al-ta'addiyah}

Dalam firman Allah, dalam surah al-Baqarah: 17,

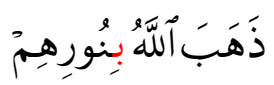

Terjemahnya:

"Allah melenyapkan cahaya yang menyinari mereka."

2. Al-sababiyah

Dalam firman Allah, surah al-Baqarah: 54,

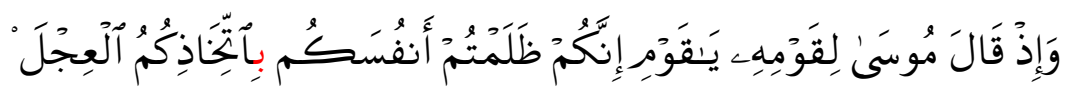

Terjemahnya:

16 Muhammad Yahya, "Kontribusi Kaidah-Kaidah Nahwu Terhadap Ushul Fikih Studi Naskah Dan Telaah Pemikiran Isnawi Dalam Kitab Al Kawakab Ad Duri Fi Takhrij Al Furu' Al Fiqhiyah 'ala Al Masaail Al Nahwiyah.”

${ }^{17}$ Taqiyuddin Abu al-Hasan Bin Abdi al-Kaafi bn Ali bin Tamam bin Hamid al-Subkiy, AlIbhaj Fi Syarhi Al-Minhaj (Beirut: Dar Al Kutub Al Ilmyah, 1995). 
"Dan (ingatlah) ketika Musa berkata kepada kaumnya, 'Wahai kaumku! Kamu benar-benar telah menzalimi dirimu sendiri dengan menjadikan (patung) anak sapi (sebagai sesembahan)'.’

\section{Al-Mushaahabah}

Dalam firman Allah, dalam surah Hud: 48,

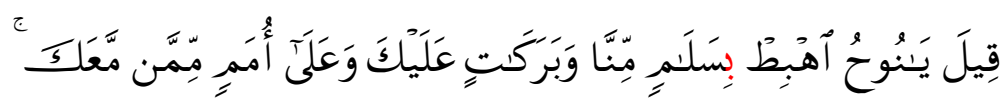

Terjemahnya:

"Difirmankan, 'Wahai Nuh! Turunlah dengan selamat sejahtera dan penuh keberkahan dari kami bagimu dan bagi semua umat (mukmin) yang bersamamu'."

4. Al-Dzarfiyah

Dalam firman Allah, dalam surah al-Qamar: 34,

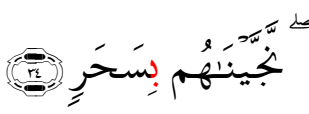

Terjemahnya:

"Kami selamatkan mereka sebelum fajar menyingsing."

\section{Al-Tab'idh}

Dalam firman Allah, dalam surah al-Insan: 6,

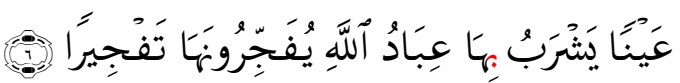

Terjemahnya:

"(Yaitu) mata air (dalam surga) yang diminum oleh hamba-hamba Allah dan mereka dapat memancarkannya dengan sebaik-baiknya."

6. Al-Ghayah

Dalam firman Allah dalam surah Yusuf: 100

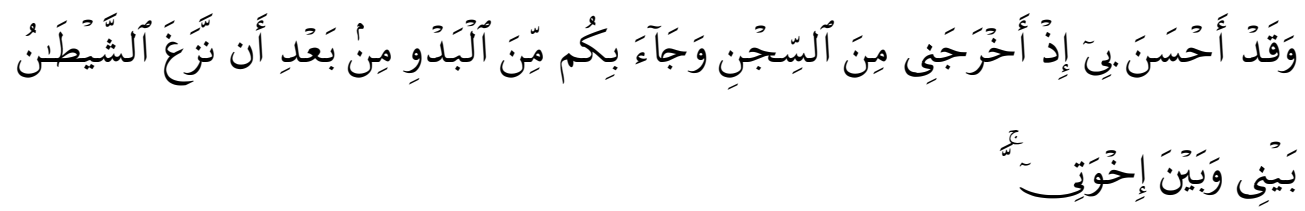

Terjemahnya:

"Sesungguhnya tuhanku telah berbuat baik kepadaku ketika Dia membebaskan aku dari penjara dan ketika membawa kamu dari dusun, setelah setan merusak (hubungan) antara aku dan saudara-saudaraku.” 
Adapun hadis, sama halnya dengan Al-Qur'an yang datang dengan berbahasa arab, memahaminya juga membutuhkan penguasaan kaidah-kaidah bahasa Arab. Sebagai contohnya, Rasulullah shallallaahu 'alaihi wa sallam bersabda,

$$
\begin{aligned}
& \text { احتج آدم وموسى، فقال له موسى: يا آدم أنت أبونا خيبتنا وأخرجتنا من الجنة، قال له آدم: يا } \\
& \text { موسى اصطفاك الله بكلامه، وخط لك بيده، أتلومني على أمر قدره الله علي قبل أن يخلقني } \\
& \text { بأربعين سنة؟ فحج آدم موسى، فحج آدم موسى " ثلاثا. }
\end{aligned}
$$

Artinya:

"Adam dan Musa pernah berbantahan. Musa berkata, 'Wahai Adam, engkau adalah bapak kami. Tetapi engkau telah mengecewakan kami karena menyebabkan kami keluar dari surga'. Adam menjawab, 'Engkau wahai Musa, engkau telah dipilih dan dimuliakan oleh Allah Subhanahu wa Ta'ala. Dengan kehendak-Nya engkau dapat bercakap-cakap dengan-Nya. Apakah engkau mencelaku karena urusan yang telah ditakdirkan Allah atasku sejak 40 tahun sebelum aku diciptakan-Nya?' Demikianlah Adam membantah Musa, demikianlah Adam membantah Musa, demikianlah Adam membantah Musa."18

Pada akhir hadis disebutkan "فحج آدم موسى". Dalam hal ini, terjadi perbedaan pendapat mengenai kedudukan Adam dan Musa. Ahlu al-Sunnah mengatakan bahwa Adam kedudukannya adalah fail marfu' dan Musa adalah maf'ul manshub. Adapun Qadariyyah berpendapat sebaliknya, Adam adalah maf'ul bih muqaddam manshub dan Musa adalah fail marfu' akan tetapi periwayat hadis tersebut mengubahnya. Dan yang rajih adalah pendapat Ahlu al-Sunnah wa al-Jamaah.

Perbedaan ini disebabkan karena berkumpulnya fail dan maf'ul bih dalam satu kalimat, dimana ulama Nahwu mengatakan, "Jika berkumpul dalam satu kalimat fäil dan maf'ūl maka terdapat empat kemungkinan: pertama: kedua-duanya shahih (tanda I'rabnya nampak), kedua: fäil-nya șahih dan maf'ūl-nya mu'tal (i'rabnya tidak nampak), ketiga: maf'ūl -nya șahih dan fäil-nya mu'tal dan yang keempat: kedua-duanya mu'tal. Pada tiga keadaan pertama boleh mendahulukan maf'ul atas fäil sebab i'rab katanya nampak. Adapun yang keempat maka wajib mendahulukan fäil kecuali ada qarinah yang menunjukkan bahwa maf'ül bih-nya didahulukan. Jelaslah bahwa pendapat Ahlu al-Sunnah merupakan pendapat yang rājih, sebab pada asalnya, fäil didahulukan atas maf'īl kecuali ada qaīnah yang menunjukkan sebaliknya. Selain itu, sepakatnya para periwayat hadis ini dalam me-rafa' kata

${ }^{18}$ Muhammad bin Ismail al-Bukhari, A- Jami' A- Musnad Al-Shahih Min Umuuri Rasulillah Wa Ayyaamihi, 1st ed. (dar Thauq al Najah, n.d.). 
Adam yang menghilangkan kemungkinan-kemungkinan lain sebagaimana yang disebutkan oleh Qadariyyah. ${ }^{19}$

Contoh lain, adalah apa yang terjadi ketika Fatimah, putri Rasulullah, meminta warisan yang ditinggalkan Rasulullah kepada Abu Bakar sebagai khalifah saat itu. Lalu Abu Bakar berkata, "Sesungguhnya aku mendengar Rasulullah shallallaahu 'alaihi wa sallam bersabda,' "مadis ini dijadikan celah oleh Syiah untuk mencela Abu Bakar radhiyallaahu 'anhu dengan mengatakan bahwa Abu Bakar telah menghalangi Fatimah radhiyallaahu 'anha mendapatkan hak warisnya. Adapun Ahlu al-Sunnah mengatakan bahwa Abu Bakar hanya mengamalkan sabda Rasulullah shallallaahu 'alaihi wa sallam.

Perbedaan Syiah dan Ahlu al-Sunnah dalam hadis ini disebabkan perbedaan pemahaman mereka terhadap hadis pada kata lo (maa). Dalam bahasa Arab, kata o ada dua yaitu ismiyah dan harfiyah. Maa ismiyah seperti maa maușulah, mașdariyah, ta'ajjubiyah dan syarțiyah. Adapun harfiyah seperti maa nafiyah dan maa käffah. Pada hadis di atas, Syiah berpendapat bahwa maa tersebut adalah maa nafiyah (peniadaan), sehingga makna hadisnya adalah "Kami tidak meninggalkan sedekah melainkan warisan". Adapun Ahlu al-Sunnah mengatakan bahwa maa dalam hadis tersebut adalah maa maușulah, sehingga maknanya adalah "Apa yang kami tinggalkan adalah sedekah (bukan warisan)". ${ }^{21}$

Tidak sampai pada dalil induk yang menjadi petunjuk untuk menentukan suatu hukum, ilmu Nahwu juga berkaitan erat dengan ilmu Ușul Fikih yang merupakan ilmu alat untuk meramu dalil-dalil tersebut. Terlihat dari banyaknya pembahasan dalam ilmu Ușul Fikih yang juga merupakan pembahasan dalam ilmu Nahwu. Salah satunya adalah Bab al-kalam, Ibn Qudamah menyebutkan bahwa kalam adalah suara yang terdengar dan huruf-huruf yang tersusun, ia terbagi menjadi dua: mufid dan tidak mufid. Adapun ahli bahasa mengkhususkan kalam dengan mufid yang mencakup mubtada khabar, fi'il fäil dan panggilan serta isim-nya, selain itu dinamakan kalimah atau qaulun. Ibnu Qudamah kemudian melanjutkan bahwa perbedaan ulama $u s ̣ u$ dan bahasa hanya terletak pada pengistilahan. ${ }^{22}$ Imam alJuwaini mengatakan bahwa kalam itu paling sedikit tersusun dari dua isim, atau isim dan fi' $i l$, atau fi 'il dan huruf, atau isim dan huruf. ${ }^{23}$

\footnotetext{
${ }^{19}$ Abdilqawiy al-Thufiy al-Sharsariy al-Hanbali, Al-Shaq'atu Al-Gadhabiyah Fi Al-Raddi 'alaa Munkirii Al-Arabiyah.

${ }^{20}$ Al-Bukhari, Al-Jami’ Al-Musnad Al-Shahih Min Umuuri Rasulillah Wa Ayyaamihi.

${ }^{21}$ Abdilqawiy al-Thufiy al-Sharsariy al-Hanbali, Al-Shaq'atu Al-Gadhabiyah Fi Al-Raddi 'alaa Munkirii Al-Arabiyah.

${ }^{22}$ Abdullah Hanbali bin Ahmad bin Muhammad bin Qudamah al-Maqdisy, Al-Rudhatu AlNadzir Wa Junnatu Al-Munadzir Fi Ushuli Al-FIqih 'alaa Madzhabi Al-Imam Ahmad Bin Hanbal, 2nd ed. (Muassatu al Rayyan li al Thiba'ah wa al Nasyr al Tauzi', 2002).

${ }^{23}$ Abdul Malik bin Abdillah bin Yususf bin Muhammad al-Juwaini, Al-Waraqaat, n.d.
} 
Selain pembahasan di atas, masih banyak lagi pembahasan uṣūl fikih yang juga merupakan pembahasan Nahwu. Di antaranya adalah penjelasan tentang isim fi'il dan huruf, bentuk kalimat perintah dan larangan, batas minimal jamak, kinayah damīr dan isyarah, al-istitsna' dan lain sebagainya. Permasalahan-permasalahan tersebut kita dapati dalam kitab-kitab ușūl fikih salah satunya adalah al-Ihkam fi Ushuli al-Ahkam karya Ibn Hazm juga al-Amidi.

Dari hal-hal itu, nyatalah betapa besar pengaruh ilmu Nahwu dalam istinbat suatu hukum fikih. Olehnya, ulama menyebutkan salah satu syarat seorang bisa dinobatkan sebagai mujtahid adalah mengetahui bahasa Arab beserta kaidah-kaidah yang berkaitan dengannya. Hal ini sebagaimana yang terdapat dalam kitab-kitab ushul fikih seperti Raudhatu al-Nazhir, al-Ibhaj, al-Waraqat, al-Thaqiq wa al-Bayan Syarh al-Burhan dan selainnya. Tentu yang menjadi penyebabnya adalah pentingnya ilmu Nahwu dalam penetapan hukum sebuah permasalahan, sehingga seorang mujtahid tidak mungkin menemukan solusi dari setiap permasalahan yang ada melainkan terdapat beberapa permasalahan yang mesti diselesaikan dengan menggunakan peran ilmu Nahwu pada hukum tersebut.

Imam al-Syafi'i rahimahullah pernah berkata, "Aku tidak pernah ditanya tentang suatu permasalahan dari masalah-masalah fikih kecuali aku menjawabnya dengan qawaid nahwiyah." 24

\section{Beberapa Permasalahan Fikih yang Ditetapkan Berdasarkan Kaidah Nahwiyah \\ 1. Ta'liq Thalaq}

Ilmu Nahwu dalam istinbat hukum fikih secara umum bisa kita lihat pengaruhnya pada permasalahan ta'liq thalaq, bahkan al-Isnawi dalam kitabnya al-Kaukab al-Durry fiimaa Yatakharraju 'alaa Ushuli al-Nahwiyah min al Furu'i al-Fiqhiyah menyebutkan permasalahan ini hampir pada setiap bab yang ia tuliskan.

Diantaranya adalah pada permasalahan hal. Dalam ilmu Nahwu kata yang menempati posisi hal hukumnya dinashab. Al-Rafi'i mengatakan: jika ada seorang suami berkata kepada istrinya 'إن دخلت الدار طالقا' (jika kamu masuk ke rumah dalam keadaan terthalaq) dan tidak melanjutkan perkataannya lagi maka ada dua kemungkinan: jika ia menashab kata thaliqan karena posisinya sebagai hal dan belum sempat menyempurnakan perkataannya maka tidak jatuh thalaq kepada istrinya. Adapun jika niatnya adalah merafak namun ia salah dalam memberi harakat maka jatuh thalaq kepada istrinya.

${ }^{24}$ Abu al-Falah Abdu al- Hayyi bin Ahmad bin Muhammad, Syazarat Al-Dzahab Fi Kahbari Man Dzahab, 1st ed. (Beirut: Daar Ibnu Katsir, 1986). 
'أنت طالق مريضة' Demikian juga jika seorang suami berkata kepada istrinya (engkau terthalaq jika dalam keadaan sakit) maka istri tidak akan terthalaq kecuali ia dalam keadaan sakit. Adapun jika kata maridhah dirafak maka secara otomatis pada keadaan tersebut jatuh thalaq untuk sang istri. ${ }^{25}$

\section{Tartib (berurutan) ketika berwudhu.}

Mazhab Syafi'i memasukkan tartib kedalam salah satu dari rukun wudhu. Berdasarkan atas firman Allah subhanahu wa ta'ala dalam surah al-Maidah:6

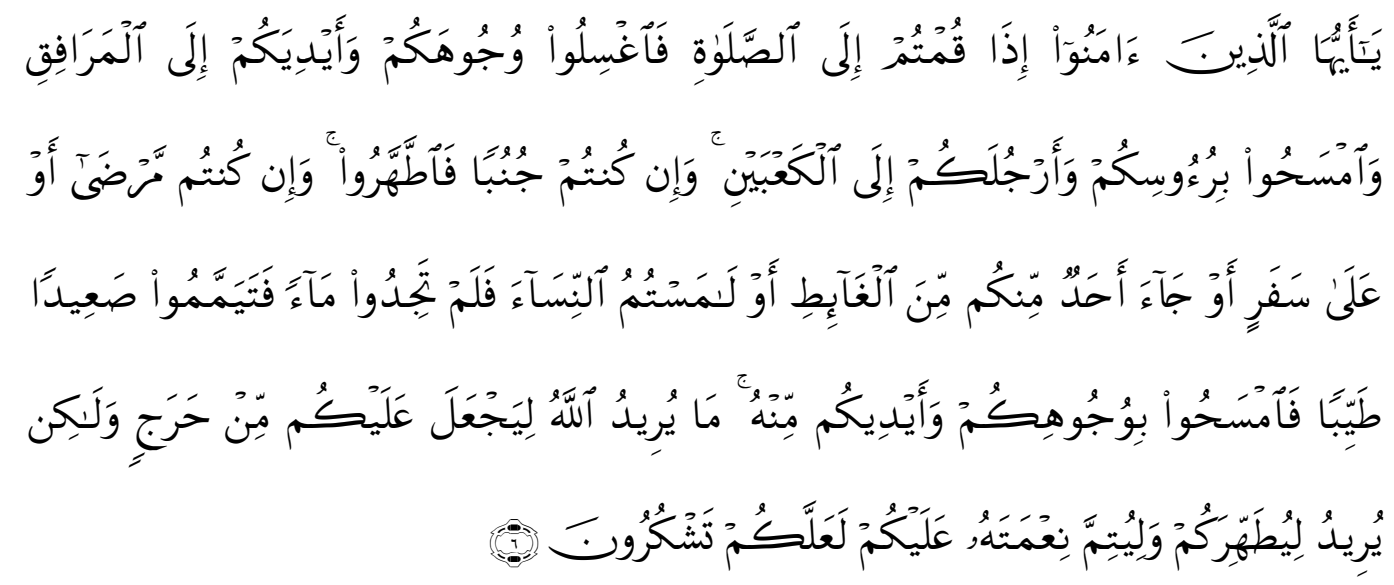

Terjemahnya:

"wahai orang-orang yang beriman! Apabila kamu hendak melaksanakan shalat, maka basuhlah wajahmu dan tanganmu sampai ke siku, dan sapulah kepalamu dan (basuhlah) kedua kakimu sampai ke kedua mata kaki. Jika kamu junub maka mandilah. Dan jika kamu sakit atau dalam perjalanan atau kembali dari tempat buang air, atau menyentuh perempuan, maka jika kamu tidak memperoleh air, maka bertayamumlah dengan debu yang baik (suci); usaplah wajahmu dan tanganmu dengan (debu) itu. Allah tidak ingin menyulitkan kamu, tetapi Dia hendak membersihkan kamu dan menyempurnakan nikmat-Nya bagimu. Agar kamu bersyukur"

Secara nampak, ayat ini tidak menyebutkan wajibnya tartib saat berwudhu, sebab penyebutan rukun-rukun wudhu diantarai dengan kata waw (dan), bukan kata yang menunjukkan tartib seperti $f a$ (lalu). Namun ulama Syafii menetapkan bahwa tartib termasuk bagian dari rukun wudhu dengan memperhatikan susunan kalimat dalam ayat, dimana satu anggota wudhu yang cara menyucikannya adalah dengan disapu, disebutkan diantara anggota wudhu lain yang cara menyucikannya adalah dengan dicuci. Sedang kebiasaan orang Arab ketika

${ }^{25}$ bin al-Hasan bin Ali al-Isnawi al-Syafi'i, Al-Kaukab Al-Durry Fiimaa Yatakharraju' “ala Ushul Al-Nahwiyah Min Al-Furu' Al-Fiqhiyah. 
menyebutkan beberapa hal yang sejenis, mereka menyebutkannya secara berdampingan dan mengathafkannya sebelum kemudian menyebutkan jenis yang lain. Dan tentu penyelisihan ayat ini terhadap kebiasaan tersebut bukan tanpa tujuan melainkan untuk menunjukkan adanya urutan pada rukun-rukun tersebut. hal ini sebagaimana dijelaskan oleh Imam al-Nawawi. ${ }^{26}$

\section{Penentuan Mustahiq Zakat}

Terdapat delapan golongan manusia yang berhak menerima zakat, mereka adalah: hal ini sebagaiman firman Allah subhanahu wa ta'ala dalam surah alTaubah: 60

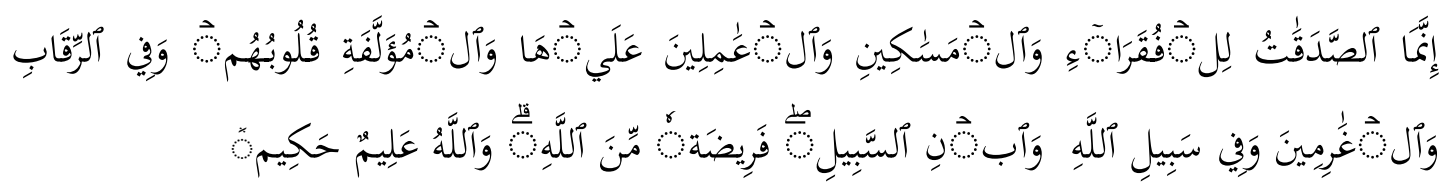

Terjemahnya:

"sesungguhnya zakat itu hanyalah untuk orang-orang fakir, orang miskin, amil zakat, yang dilunakkan hatinya (muallaf), untuk (memerdekakan) hamba sahaya, untuk (membebaskan) orang yang berhutang, untuk jalan Allah dan untuk orang yang sedang dalam perjalanan. Sebagai kewajiban dari Allah, Allah Maha mengetahui, Maha bijaksana"

Jumhur ulama berpendapat bolehnya memberikan zakat kepada satu-satu orang dari salah satu golongan yang disebutkan dalam ayat. Ini adalah pendapat Umar, Hudzaifah dan ibn Abbas radhiyallaahu anhum dari kalangan sahabat, demikian juga Said bin Jubair, al-Hasan, dan 'Athaa' rahimahumullah dari kalangan tabiin.

Adapun al-Nakha'i berkata: “jika zakat yang dikeluarkan banyak dan mencukupi delapan golongan yang tersebut dalam ayat maka dibagikan ke delapan golongan. Adapun jika sedikit, maka boleh memberikannya pada satu golongan saja”. Imam Malik berkata: "mempertimbangkan siapa yang paling butuh diantara mereka dan mendahulukannya".

Selain pendapat diatas, terdapat sebahagian ulama yang mengatakan wajibnya memberikan zakat kepada delapan golongan yang disebutkan dalam ayat dan setiap golongan setidaknya minimal tiga orang yang menerima zakat. Ini sebagaimana yang disebutkan oleh Ikrimah dan Imam al-Syafii, mereka berkata: "wajib membagikan harta zakat kepada delapan golongan dengan pembagian yang sama rata. Dan setiap golongan minimal terdapat tiga orang penerima zakat. Adapun jika tidak mendapatkan melainkan satu orang dari setiap golongan, maka cukup memberikannya pada satu orang tersebut. ${ }^{27}$

\footnotetext{
${ }^{26}$ Al-Nawawi, Al-Majmu' Syarah Al-Muhazzab.

${ }^{27}$ Abdullah bin Ahmad bin Muhammad bin Qudamah al-Maqdisy Al-Hanbaliy, Al-Mughniy (Kairo: Makatabah al Qahirah, 1968).
} 
Pendapat ini berdasarkan konteks ayat dalam firman Allah pada surah alTaubah di atas. Pada ayat tersebut disebutkan shigah al hashr (innama) lalu kemudian laam al-tamliik (lii) dan juga penggunaan waw sebagai huruf athaf yang bermakna al-tasyrik. Uslub ini menunjukkan adanya kesamaan hak dari delapan golongan yang disebutkan dalam ayat dan wajibnya membagikan harta zakat dengan takaran yang sama kepada mereka tanpa mendahulukan satu golongan atas golongan yang lainnya. Adapun dalil bahwa setiap golongan setidaknya terdapat minimal tiga orang yang menerima zakat adalah penyebutan bentuk jamak dalam ayat tersebut seperti al-fuqara' dan al-masaakin, sedang jumhur ulama berpendapat bahwa angka minimal dari jamak adalah tiga. ${ }^{28}$

Hal ini sebagaimana yang dikatakan oleh Abu Bakar: "sebab Allah subhanahu wa ta'ala menjadikan zakat untuk mereka seluruhnya dan mengikutsertakan delapan golongan dalam harta zakat tersebut sehingga tidak boleh mencukupkan pada sebahagiannya saja". ${ }^{29}$

Namun pendapat yang rajih adalah apa yang dipilih oleh jumhur berdasarkan beberapa dalil pendukung lainnya. salah satunya adalah sabda Rasulullah shallallaahu 'alaihi wa sallam kepada Muaz radhiyallaahu 'anhu:

$$
\begin{aligned}
& \text { إنك تأتي قوما من أهل الكتاب، فادعهم إلى شهادة أن لا إله إلا الله وأين رسول الله، فإن هم } \\
& \text { أطاعوا لذلك، فأعلمهم أن الله افترض عليهم خمس صلوات في كل يوم وليلة، فإن هم أطاعوا } \\
& \text { لذلك، فأعلمهم أن الله افترض عليهم صدقة تؤخذ من أغنيائهم فترد في فقرائهم، فإن هم أطاعوا } \\
& \text { لذلك، فإياك وكرائم أموالهم، واتق دعوة المظلوم، فإنه ليس بينها وبين الله حجاب. }
\end{aligned}
$$

Artinya:

"Ketika Nabi shallallahu 'alaihi wa sallam mengutus Mu'adz ke Yaman, ia pun berkata padanya, "Sesungguhnya engkau akan mendatangi kaum dari ahli kitab. Maka jadikanlah dakwah engkau pertama kali pada mereka adalah supaya mereka mentauhidkan Allah Ta'ala. Jika mereka telah memahami hal tersebut, maka kabari mereka bahwa Allah telah mewajibkan pada mereka shalat lima waktu sehari semalam. Jika mereka telah shalat, maka kabari mereka, bahwa Allah juga telah mewajibkan bagi mereka zakat dari harta mereka, yaitu diambil dari orang-orang kaya di antara mereka dan disalurkan untuk orang-orang fakir di tengah-tengah mereka. Jika mereka menyetujui hal itu, maka ambillah dari harta mereka, namun hati-hati dari harta berharga yang mereka miliki , 30

\footnotetext{
${ }^{28}$ bin Abdilqawiy al-Thufiy al-Sharsariy al-Hanbali, Al-Shaq'atu Al-Gadhabiyah Fi Al-Raddi 'alaa Munkirii Al-Arabiyah.

${ }^{29}$ Al-Hanbaliy, Al-Mughniy.

${ }^{30}$ Muslim bin Hajjaj Al-Naisabury, Al-Musnad Al-Shahih Al-Mukhtasar Binaqli Al-'Adli 'an Adli Ilaa Rasulillah (Beirut: Daar al Turats Al Arabiyah, n.d.).
} 
Dalam hadis ini Rasulullaah shallallaahu 'alaihi wa sallam hanya menyebutkan satu golongan saja yaitu fuqara'.

Contoh lain adalah apa yang diriwayatkan bahwa al-Kisai pernah berkata: "suatu ketika aku duduk bersama Abu Yusuf di sisi khalifah Harun al-Rasyid, lalu Abu Yusuf seakan-akan meremehkan ilmu Nahwu. Aku berkata kepadanya (untuk memahamkan pentingnya ilmu Nahwu): 'bagaimana menurutmu jika ada seseorang yang berkata: anaa qatilun gulamaka (dengan menashab kata gulam karena maf'ul bih, artinya adalah aku membunuh anakmu), dan yang lainnya lagi berkata: anaa qatilu gulamika (dengan menjarr kata gulam karena mudhaf ilaih)? Yang mana diantara kedua orang tersebut yang akan engkau hukum?'. Abu Yusuf berkata: 'dua-duanya akan aku hukum'. Harun lalu berkata: 'engkau salah wahai Abu Yusuf'. Mendengar itu Abu Yusuf merasa malu: 'lalu bagaimana?'. Harun menjawab: 'yang dihukum adalah yang mengatakan anaa qatilu gulamika sebab itu bermakna fi'il madhi, telah terjadi. Adapun yang mengatakan anaa qaitilun gulamaka maka tidak dihukum karena ia belum melakukannya, sebagaimana firman Allah dalam surah al-Kahfi: 23

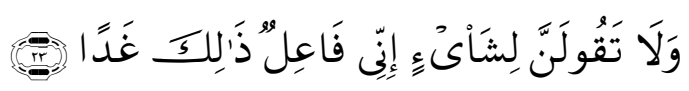

Terjemahnya:

"dan jangan sekali-kali engkau mengatakan terhadap sesuatu 'aku pasti melakukan itu besok pagi",31.

Demikian juga jika pada permasalahan 'adad dan ma'dud, dalam kaidah Nahwu dikatakan bahwa untuk bilangan tiga sampai sepuluh, 'adad menyelisihi ma'dud dalam hal pemuzakkaran dan penta'nitsan (muzakkar dan muannats). Olehnya al-Rafi'i mengatakan bahwa: jika ada seseorang yang berkata 'berikan dia sepuluh unta, maka kita lihat pada kata sepuluh yang ia ucapkan. Jika menggunakan ta' al-marbuthah ('asyarah) berarti unta yang diberikan adalah unta jantan dan jika tidak menggunakan ta' al-marbuthah ('asyara) berarti unta yang diberikan adalah unta betina. Namun yang rajih adalah boleh keduaduanya. ${ }^{32}$

Faktor-Faktor yang Menyebabkan Ulama Berbeda Pendapat pada Masalah Fikih

\section{Perbedaan dalam memahami Gramatika Bahasa Arab}

\footnotetext{
${ }^{31}$ Abu Abdillah Yaqut bin Abdillah Al-Rumiy, Mu'jamu Al-Udabaa, 4th ed. (Beirut: Daar Al- Gharb Al-Islamiy, 1993).

${ }^{32}$ Abdurrahim bin al Hasan bin Ali al-Isnawi al-Syafi'i, Al-Kaukab Al Durry Fiimaa Yatakharraju' "alaa Ushul Al-Nahwiyah Min Al Furu' Al-Fiqhiyah.
} 
Ilmu Nahwu yang memiliki peran besar dalam penetapan hukum-hukum fikih, menjadi salah satu sebab adanya perbedaan pendapat di kalangan ulama mengenai hukum beberapa permasalahan yang ditetapkan, hal ini disebabkan perbedaan mereka dalam penggunaan kaidah nahwu pada sebuah nash baik al qur'an maupun sunnah. Berikut adalah beberapa contoh dari permasalahanpermasalahan tersebut:

\section{a. Perbedaan Syafiiyah Dan Malikiyah Pada Permasalahan Batas Wajib Penyapuan Kepala Ketika Berwudhu.}

Allah subhanahu wa ta'ala berfirman dalam surah al-Maidah: 6

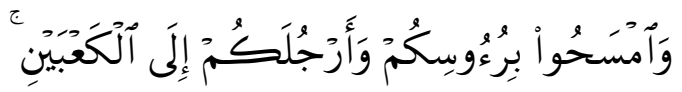

Terjemahnya:

"dan sapulah kepalamu dan (basuhlah) kedua kakimu sampai ke kedua mata kaki"

Dari ayat ini, ulama berbeda pendapat mengenai batasan kepala yang wajib dibasuh. Hal ini disebabkan oleh perbedaan dalam memahami makna $B a^{\prime}$ pada kata biruusikum. Ulama Syafiiyah mengatakan bahwa ba' di sini littab'idh sehingga cukup membasuh sebahagian kepala ketika berwudhu. Adapun Malikiyah memandang bahwa $b a^{\prime}$ dalam ayat tersebut adalah zaaidah dan menunjukkan penekanan sehingga wajib membasuh keseluruhan kepala. ${ }^{33}$

\section{b. Perbedaan Jumhur Dan Sebahagian Kecil Ulama Pada Permasalahan Cara Mencuci Kaki Ketika Berwudhu.}

Allah subhanahu wata'ala berfirman dalam surah Al Maidah: 6

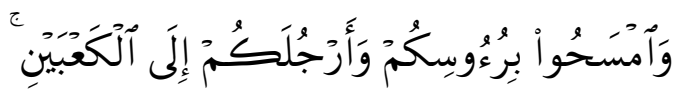

Terjemahnya:

"dan sapulah kepalamu dan (basuh) kedua kakimu sampai ke kedua mata kaki"

Dari ayat ini ulama berbeda pendapat mengenai tata cara mencuci kaki, hal ini disebabkan perbedaan bacaan pada kata arjul apakah huruf lam dibaca fathah atau kasrah?

Jumhur mengatakan huruf lam dalam ayat ini dibaca fathah dan mengathaf kepada kata wujuhakum sehingga kaki wajib dicuci sebagaimana wajah, dan ini sesuai dengan qiraah yang masyhur. Adapun sebahagian ulama berpendapat

\footnotetext{
${ }^{33}$ Muhammad bin Ahmad bin Muhamma bin Ahmad bin Rusyd Al Qhurthubiy, Bidayatu AlMujtahid Wa Nihayatu Al-Muqtashid, 1st ed. (Kairo: Daar Al Hadits, 2004).
} 
bahwa lam pada ayat tersebut dibaca kasrah dan mengathaf pada kata ru'uusikum sehingga kaki cukup disapu sebagaimana kepala. ${ }^{34}$

\section{c. Perbedaan Syafiiyah Dan Hanafiyah Pada Permasalahan Janin Yang Induknya Disembelih}

Dalam hadis riwayat Abu Daud yang berbunyi:

$$
\begin{aligned}
& \text { قال مُسدَّد: قال: قلنا: يا رسولَ اللهِه، ننحرُ الناقةَ ونَذَبَحُ البقرةَ أو الشاةَ، في بطنِها الجنينَ، أنُلقِيه } \\
& \text { أم نأكلُه؟ فقال: "كلؤه إن شئتُم، فإن ذكاتَه ذكاة أمّه }
\end{aligned}
$$

Artinya:

Musaddad berkata: kami berkata:

"wahai Rasulullaah, kami berqurban dengan unta dan menyembelih sapi atau kambing yang dalam perutnya ada janin. Apakah kami membuangnya atau boleh kami makan?"

Rasulullaah shallallaahu 'alaihi wa sallam:

"makanlah jika kalian menghendakinya, karena sembelihannya adalah sembelihan induknya" (HR. Abu Daud). ${ }^{35}$

Dari hadis ini ulama berbeda pendapat apakah janin dari induk yang telah disembelih boleh dimakan atau tidak. Al-Syafi'i berpendapat bahwa janin tersebut halal dimakan sebab sembelihannya telah terwakili oleh sembelihan induknya. Adapun Hanafiyah berpendapat bahwa sembelihan induk tidak bisa mewakili sembelihan janinnya. ${ }^{36}$

Perbedaan pendapat ini salah satunya disebabkan oleh perbedaan riwayat hadis yang sampai ke para ulama. Riwayat pertama dan masyhur adalah mendhammahkan ta' marbuthah pada kata dazkaatu ummihi karena kedudukannya adalah khabar marfu', sehingga ma'nanya adalah sembelihan janin itu merupakan sembelihan induknya, maksudnya sudah terwakili dengan sembelihan induknya. Adapun riwayat yang kedua adalah menfathahkan ta' marbuthah pada kata tersebut, karena kedudukannya adalah maf'ul muthlaq manshub dari fi'il mahzuf taqdirnya dzakaatu al janin an yudzka zakaata

${ }^{34}$ Muhammad bin Ahmad bin Abi Bakar bin Farah Al Qurthubiy, Al Jami' Liahkami Al Qur'an, 2nd ed. (Kairo: Daar Kutub Al Mishriyah, 1964).

${ }^{35}$ Abu Daud Sulaiman bin al-Asy'ats bin Ishaq bin Basyir bin Syaddad bin Amru al-Azdiy Al Sijistani, Sunan Abi Daud, 1st ed. (daar Al Risalah Al "Alamiyah, 2009).

${ }^{36}$ Muhammad bin Ahmad bin Abi Sahl Al-Sarkasyiy, Al-Mabsuth, 12th ed. (Beirut: Daar Al Ma'rifah, 1993). 
ummihi, sehingga ma'nanya adalah janin wajib disembelih seperti sembelihan induknya. $^{37}$

\section{d. Perbedaan ulama pada permasalahan jumlah minimal saudara yang bisa menghalangi ibu mendapatkan sepertiga dari harta warisan}

Ulama telah bersepakat bahwa keberadaan sejumlah saudara mayyit dapat mengurangi bagian harta warisan yang diperoleh ibu dari mayyit tersebut, dimana sebelumnya ia memperoleh sepertiga dari harta yang ditinggalkan, namun adanya sejumlah saudara mayyit menjadikan ia memperoleh seperenam dari harta yang ditinggalkan. Hal ini berdasarkan firman Allah subhanahu wa ta'ala dalam surah al-Nisa: 11

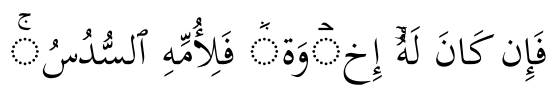

Terjemahnya:

"jika dia (yang meninggal) mempunyai beberapa saudara, maka ibunya mendapat seperenam"

Namun terjadi perbedaan pendapat antara jumhur ulama dan ibn 'Abbas radhiyallaahu 'anhuma pada permasalahan minimal jumlah saudara yang dapat menjadi penghalang ibu mendapatkan sepertiga. Jumhur mengatakan bahwa keberadaan dua saudara baik laki-laki maupun perempuan sudah dapat mengurangi bahagian yang diperoleh ibu menjadi seperenam. Adapun ibn 'Abbas mengatakan bahwa jumlah mereka mesti mencapai tiga atau lebih.

Perbedaan ini didasari dengan perbedaan pada penentuan batas minimal jamak. Yang berpendapat bahwa minimal jamak adalah dua maka mereka mengatakan bahwa ibu memperoleh seperenam dengan keberadaan dua atau lebih saudara mayyit. Dan yang berpendapat bahwa minimal jamak adalah tiga, mengatakan bahwa jumlah saudara yang dapat mengurangi bahagian ibu adalah tiga atau lebih. ${ }^{38}$

Namun pendapat yang lebih rajih adalah pendapat jumhur, dan inilah yang dipilih oleh Syaikh Shalih al-Fauzan beradasarkan ijma' sahabat sebelum datang ibn 'Abbas menyebutkan pendapat yang menyelisihi. ${ }^{39}$

Demikian juga yang dimaksudkan dengan tatsniyah adalah jam'u syai'in ilaa mitslihi (menggambungkan sesuatu dengan yang semisalnya), maka secara makna tatsniyah termasuk jamak. ${ }^{40}$

\footnotetext{
${ }^{37}$ Abu al-'Abbas Syihabuddin Ahmad bin Idris bin Abdirrahman Al-Qarrafi, Al-Dzakhirah, 4th ed. (Beirut: Daar Al Gharb Al Islamiy, 1994).

${ }^{38}$ Al-Qhurthubiy, Bidayatu Al-Mujtahid Wa Nihayatu Al-Muqtashid.

${ }^{39}$ Shalih bin Fauzan bin Abdillah Al-Fauzan, Al-Tahqiqat Al-Mardhiyah Fi Al-Mabahits AlFardhiyah, 3rd ed. (Riyadh: Makatabatu Al Ma'arif, 1986).
} 


\section{KESIMPULAN}

Berdasarkan uraian di atas dapat disimpulkan bahwa:

1. Ilmu Nahwu memiliki pengaruh besar dalam istinbat hukum fikih. Hal itu disebabkan karena sumber dalil syariat (Al-Qur'an dan sunnah) berbahasa arab. sehingga untuk memahaminya dengan benar dibutuhkan penguasaan terhadap ilmu bahasa Arab, salah satunya adalah ilmu Nahwu. Sehingga adanya perbedaan ulama pada hukum beberapa permasalahan fikih disebabkan oleh perbedaan mereka dalam qawaid nahwiyyah. Contoh keterkaitan ilmu Nahwu dengan pemahaman terhadap makna ayat dalam AlQur'an adalah pada penggunaan huruf $\mathrm{Ba}$ ' sebagai huruf jar yang mempunyai beberapa makna.

2. Beberapa permasalahan fikih yang ditetapkan berdasarkan qaidah nahwiyah, yaitu : Ta'liq talaq, tartib Wudu, mustahiq zakat.

3. Faktor yang menyebabkan mengapa Ulama berbeda pendapat pada masalah Fikih adalah perbedaan dalam memahami Gramatika bahasa Arab, seperti Batas wajib menyapu kepala ketika berwudu, cara mencuci kaki, janin yang disembelih induknya, serta harta warisan.

\section{DAFTAR PUSTAKA}

Abdil Kaafi bn Ali bin Tamam bin Hamid al Subkiy, Taqiyuddin Abul Hasan Bin. Al Ibhaj Fi Syarhi Al Minhaj. Beirut: Dar Al Kutub Al Ilmyah, 1995.

Abdilqawiy al Thufiy al Sharsariy al Hanbali, Sulaiman bin. Al Shaq'atu Al Gadhabiyah Fi Al Raddi 'alaa Munkirii Al Arabiyah. 1st ed. Al Waliy al Islamiy, 2013.

Abdul Hayyi bin Ahmad bin Muhammad, Abul Falah. Syazarat Al Dzahab Fi Kahbari Man Dzahab. 1st ed. Beirut: Daar Ibnu Katsir, 1986.

Abdullah al Urami al 'Alawi, Muhammad al Amiin Bin. Al Kaukab Al Wahhaj Wa

Al Raudh Al Bahhaj Fi Syarhi Shahih Muslim Bin Hajjaj. 1st ed. Daar al Minhaj, 2009.

Ahmad. "Artikulasi Ilmu Nahwu Dalam Kehidupan (Studi Analisis Makna I'rab Kitab Al Jurumuyah Menggunakan Semantika Dalalah Lafzhiyah Dalam Ushul Fikih.” Jurnal Pendidikan Dan Pranata Islam, SYAIKHUNA 10, no. 2 (2019): 194.

Ahmad al Dzahaby, Syamsuddin Muhammad bin. Taarikh Al Islam Wa Wafayaat Al Masyaahir Wa Al A'lam. Bierut: Dar al Kutub al 'Arabiy, n.d.

${ }^{40}$ Muhammad bin Ahmad bin Abi Bakar bin Farah Al-Qurthubiy, Al-Jami' Li Ahkami AlQur'an, 2nd ed. (Kairo: Daar Kutub Al Mishriyah, 1964). 
Ahmad Al Fakihi, Abdullah Bin. Syarah Kitab Al Hudud Fi Al Nahwi. Maktabah Wahbah, n.d.

Ahmad bin Muhammad, Abdul Hayyi bin. Syazaraat Al Dzahab Fi Akhbari Man Dzahab. 1st ed. Beirut: Daar Ibnu Katsir, 1986.

al Hasan bin Ali al Isnawi al Syafi'i, Abdurrahim bin. Al Kaukab Al Durry Fiimaa Yatakharraju' "alaa Ushul Al Nahwiyah Min Al Furu” Al Fiqhiyqh. 1st ed. Urdun: Dar 'Ammar, n.d.

Ali Bin Muhammad Hamid, Muhammad Bin. Mausu'ah Kasysyaf Al Funn Wa Al 'Uluum. 1st ed. Beirut: Maktabah Labnan Nasyirun, 1996.

Bukhari, Muhammad bin Ismail Al. Al Jami' Al Musnad Al Shahih Min Umuuri Rasulillah Wa Ayyaamihi. 1st ed. dar Thauq al Najah, n.d.

Fauzan, Shalih bin Fauzan bin Abdillah Al. Al Tahqiqat Al Mardhiyah Fi Al Mabahits Al Fardhiyah. 3rd ed. Riyadh: Makatabatu Al Ma'arif, 1986.

Hanbali, bin Ahmad bin Muhammad bin Qudamah al Maqdisy al, Abdullah. Raudhatu Al Nadzir Wa Junnatu Al Munadzir Fi Ushuli Al Fqih 'alaa Madzhabi Al Imam Ahmad Bin Hanbal. 2nd ed. Muassatu al Rayyan li al Thiba'ah wa al Nasyr al Tauzi', 2002.

Hanbaliy, Abdullah bin Ahmad bin Muhammad bin Qudamah al Maqdisy Al. Al Mughniy. Kairo: Makatabah al Qahirah, 1968.

Imrithy, Yahya al. Nazham Al Jurumiyah Al Imrity. Maktabah Islamiyah, n.d.

Juwaini, Abdulmalik bin Abdillah bin Yususf bin Muhammad Al. Al Waraqaat, n.d.

MUhammad Bin Abd AL Razzaq Al Husainy, Muhammad Bin. Taaj Al "arus Min Jawahir Al Qamu. 40th ed. Daar Al Hidayah, n.d.

Muhammad Yahya, Syarif. "Kontribusi Kaidah-Kaidah Nahwu Terhadap Ushul Fikih.” Tesis, 2021.

—. "Kontribusi Kaidah-Kaidah Nahwu Terhadap Ushul Fikih Studi Naskah Dan Telaah Pemikiran Isnawi Dalam Kitab Al Kawakab Ad Duri Fi Takhrij Al Furu' Al Fiqhiyah 'ala Al Masaail Al Nahwiyah.” Tesis, 2021.

Muhyiddin Abdul Hamid, Muhammad. Al Tuhfah Al Saniyah Bi Syarhi Muqaddimatil Ajrumiyah. Damaskus: Maktabah Darul Fajr, n.d.

Naisabury, Muslim bin Hajjaj Al. Al Musnad Al Shahih Al Mukhtasar Binaqli Al 'Adli 'an Adli Ilaa Rasulillah. Beirut: Daar al Turats Al Arabiyah, n.d.

Nawawi, Muhyiddin Yahya bin Syaraf Al. Al Majmu' Syarah Al Muhazzab. 1st ed. Dar al Fikri, n.d.

Qarrafi, Abul 'Abbas Syihabuddin Ahmad bin Idris bin Abdirrahman Al. Al Dzakhirah. 4th ed. Beirut: Daar Al Gharb Al Islamiy, 1994.

Qhurthubiy, Muhammad bin AHmad bin Muhamma bin Ahmad bin Rusyd Al. Bidayatul Mujtahid Wa Nihayatul Muqtashid. 1st ed. Kairo: Daar Al Hadits, 2004.

Qurthubiy, Muhammad bin Ahmad bin Abi Bakar bin Farah Al. Al Jami' Liahkami 
Al Qur'an. 2nd ed. Kairo: Daar Kutub Al Mishriyah, 1964.

Rumiy, Abu Abdillah Yaqut bin Abdillah Al. Mu'jamu Al Udabaa. 4th ed. Beirut: Daar Al Gharb Al Islamiy, 1993.

Sarkasyiy, Muhammad bin Ahmad bin Abi Sahl Al. Al Mabsuth. 12th ed. Beirut: Daar Al Ma'rifah, 1993.

Sijistani, Abu Daud Sulaiman bin al Asy'ats bin Ishaq bin Basyir bin Syaddad bin Amru al Azdiy Al. Sunan Abi Daud. 1st ed. daar Al Risalah Al "Alamiyah, 2009. 